\title{
Effect of infusion rate of indomethacin on cerebrovascular responses in preterm neonates
}

\author{
P COLDITZ, ${ }^{*}$ D MURPHY, $\dagger$ P ROLFE, $\dagger$ AND A R WILKINSON* \\ *Neonatal Unit, Department of Paediatrics, and tCentre for Biomedical Engineering, \\ University of Oxford, Oxford
}

SUMMARY Cerebrovascular responses were studied in preterm infants by Doppler ultrasound and cerebral electrical impedance for one hour after intravenous indomethacin infusion for patent ductus arteriosus. Indomethacin in a dose of $0.2 \mathrm{mg} / \mathrm{kg}$ body weight was infused over five minutes in one group of infants (20 doses) and over 20 minutes in a second group of infants (16 doses). There were no significant differences between the two groups in birth weight (mean=1068 g, range 569-1950), gestational age (mean 28.4 weeks, range 25-31), or postnatal age (mean $18 \cdot 1$ days, range $6-42$ ).

There was a significant reduction in both the Doppler mean flow velocity in the anterior cerebral artery (mean (SE) -20 (4.2)\%) and peak amplitude of cerebral electrical impedance $(-26(3.9) \%)$ within two minutes of starting the indomethacin infusion over five minutes. There was no significant change after the infusion over 20 minutes. There were no significant changes in blood pressure or carbon dioxide tensions after infusion at either rate. The results suggest that infusion of indomethacin over five minutes caused a potentially deleterious reduction in cerebral blood flow. No such reduction occurred when it was infused over 20 minutes.

Indomethacin is widely used to close haemodynamically important patent ductus arteriosus in neonates. ${ }^{12}$ Its pharmacokinetics have been studied $^{3-6}$ and its comparative safety established in a collaborative study with a one year follow up. ${ }^{7}$ Various dose regimens have been studied to maximise the clinical efficacy. ${ }^{89}$

Concern arose recently after the observation that therapeutic doses of indomethacin given to preterm neonates may cause a reduction in Doppler blood flow velocity in intracranial arteries. ${ }^{10} 11$ Cowan ${ }^{10}$ found a reduction of up to $75 \%$ in mean Doppler flow velocity in the intracranial arteries after four doses of $0.2 \mathrm{mg} / \mathrm{kg}$ body weight had been given in less than three minutes. Evans et $\mathbf{l}^{11}$ found a mean reduction of $39 \%$ after 15 doses of $0.2 \mathrm{mg} / \mathrm{kg}$ body weight had been given within 15 seconds. Cerebral blood flow measured by the ${ }^{133}$ xenon clearance technique has been reported to fall by a mean of $22 \%$ after six doses of $0.2 \mathrm{mg} / \mathrm{kg}$ body weight were given over one minute. ${ }^{12}$

Reduction in cerebral blood flow has also been reported in the fetuses and newborns of several animal species. ${ }^{13-16}$ This may be caused by constriction of the microvasculature $e^{17-19}$ in response to inhibition of prostaglandin synthesis within the endothelium. ${ }^{20}$ Extrapolating from the result that the largest reduction in cerebral blood flow velocity occurred after the fastest infusion, Cowan ${ }^{10}$ recommended that indomethacin be given slowly over at least five minutes.

This study was designed to investigate whether cerebrovascular responses measured by both Doppler ultrasound and cerebral electrical impedance were different when indomethacin was infused over five minutes from when it was infused over 20 minutes.

\section{Patients and methods}

The study was performed in two stages. The effect of indomethacin sodium trihydrate (Indocid PDA) infused over five minutes was studied after 20 doses in seven patients. In a further five patients the infusion period was changed to 20 minutes and the response after 16 doses was studied.

Each infant had clinical evidence of a haemodynamically important patent ductus arteriosus and they were all either receiving artificial ventilation or oxygen by headbox. All had received medical 
treatment consisting of fluid restriction and (in most cases) diuretics for at least 48 hours before the indomethacin was given. In 11 patients cross sectional echocardiography was done, and the presence of an important patent ductus arteriosus confirmed by a left atrial to aortic root diameter ratio of greater than $1 \cdot 4: 1$. Clinical details of the infants are shown in the table.

Indomethacin was given intravenously in a dose of $0.2 \mathrm{mg} / \mathrm{kg}$ on three occasions 12 hours apart. Arterial or capillary carbon dioxide tensions were measured before the indomethacin was given. During 10 doses, transcutaneous carbon dioxide tensions were monitored continuously, as were heart rate and peripheral or umbilical arterial blood pressure during 20 doses.

Cerebral electrical impedance was measured as previously described. ${ }^{21}$ The cardiac-synchronous pulsatile impedance change was digitised and 16 cardiac-synchronous wave forms averaged by a dedicated microprocessor. This signal reflected the changes in cranial blood volume during the cardiac cycle. The signal was recorded continuously by chart recorder, and the peak amplitude of cerebral electrical impedance measured. This measurement correlates in infants with the direction of change in cerebral blood flow estimated by ${ }^{133}$ xenon clearance. $^{22}$

Doppler ultrasound examination of blood flow velocity in the anterior cerebral artery was carried out through the anterior fontanelle with a continuous wave system using fast Fourier analysis of the Doppler frequency shift spectrum (Angioscan III). A $4 \mathrm{MHz}$ probe was used in larger babies and an $8 \mathrm{MHz}$ probe in smaller babies. The maximum signal was sought using sound and visual display of the spectrum from the region of the anterior cerebral artery. The Angioscan automatically calculated a mean frequency shift from the spectral information averaged over a memory block that varied from four to six heart beats, depending on the heart rate. The percentage change from the average of the three baseline measurements of the mean frequency shift was calculated. Doppler examinations were made intermittently, with the probe removed between examinations.

The repeatability of the two methods was calculated to ascertain whether any observed changes might be accounted for by poor repeatability of the techniques. The repeatability coefficient (defined as the limits within which $95 \%$ of the differences between two measurements of the same process lay) ${ }^{23}$ was calculated from baseline measurements made one and three minutes before indomethacin was given, making certain that the clinical state of the baby was stable during this period.

Doppler examinations were carried out and peak amplitude of cerebral impedance noted at one, two, four, six, eight, and 10 minutes, and then at five minute intervals to one hour from the time indomethacin infusion was started.

Results are shown as mean (SE). Differences between the impedance and Doppler measurements before and after indomethacin were sought by two way analysis of variance, and if a significant difference existed the paired $t$ test was used to establish the significance of differences between individual measurements. A p value of $<0.05$ was accepted as significant. The influence of gestational and postnatal age on responses was assessed by multiple linear regression analysis.

\section{Results}

The responses of Doppler mean flow velocity and cerebral electrical impedance after infusion of indomethacin over five minutes are shown in figs 1 and 2. The maximum reduction in Doppler mean flow velocity $(-20(4 \cdot 2) \%)$ occurred four minutes after starting the infusion, and the maximum reduction of cerebral electrical impedance $(-26(3.9) \%)$ occurred by one minute; these values were significantly different from the baseline values $(p<0.01$ in both cases). The responses after indomethacin

Table Comparability of the groups

\begin{tabular}{|c|c|c|c|c|c|}
\hline \multicolumn{3}{|c|}{ Five minute infusion } & \multicolumn{3}{|c|}{20 Minute infusion } \\
\hline Birth weight $(g)$ & $\begin{array}{l}\text { Gestational } \\
\text { age (weeks) }\end{array}$ & $\begin{array}{l}\text { Postnatal } \\
\text { age (days) }\end{array}$ & Birth weight $(g)$ & $\begin{array}{l}\text { Gestational } \\
\text { age (weeks) }\end{array}$ & $\begin{array}{l}\text { Postnatal } \\
\text { age (days) }\end{array}$ \\
\hline 1340 & 29 & 6 & 1005 & 27 & 42 \\
\hline 642 & 26 & 7 & 569 & 25 & 8 \\
\hline 601 & 26 & 11 & 1123 & 27 & 8 \\
\hline 1950 & 32 & 7 & 891 & 28 & 10 \\
\hline 1100 & 31 & 21 & 1414 & 31 & 11 \\
\hline 883 & 28 & 7,26 & 1109 & 30 & 11 \\
\hline 1259 & 29 & 8 & & & \\
\hline
\end{tabular}




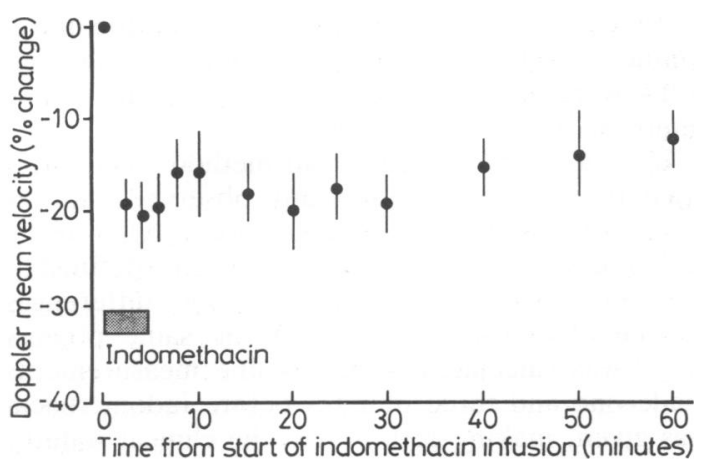

Fig 1 Percentage change of Doppler mean flow velocity in the anterior cerebral artery after indomethacin infusion over five minutes. Figures are mean (SE).

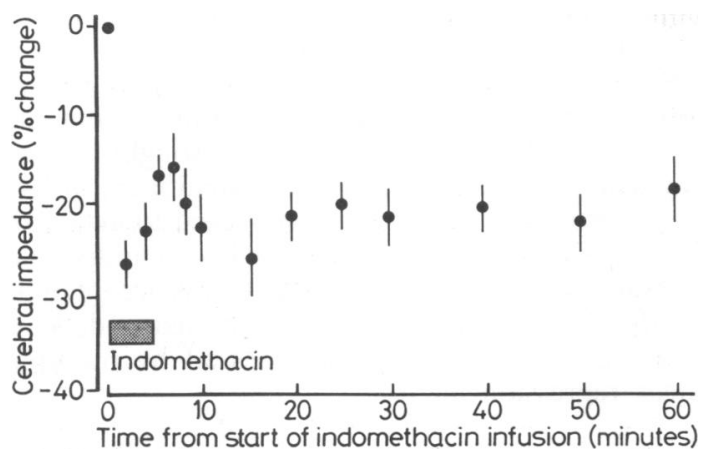

Fig 2 Percentage change of cerebral electrical impedance peak amplitude after indomethacin infusion over five minutes. Figures are mean (SE).

infusion over 20 minutes are shown in figs 3 and 4 . There was a slight reduction $(-4 \cdot 2(2 \cdot 3) \%)$ in Doppler flow velocity and an increase $(7 \cdot 4(4 \cdot 0) \%)$ in cerebral electrical impedance, but these were not significantly different from the baseline values.

Responses to the first, second, and third doses of indomethacin infused over five minutes were not significantly different. The maximum changes in Doppler mean flow velocity for the three doses was $-18(2 \cdot 1) \%,-22(4 \cdot 1) \%$, and $-20(5 \cdot 4) \%$; for cerebral electrical impedance they were $-20(6) \%,-26(3.2) \%$, and $-30(7 \cdot 8) \%$, respectively.

There was no obvious trend in the continuous blood pressure recording after indomethacin given over either five or 20 minutes. Transcutaneous carbon dioxide tensions changed inconsistently and apparently independently of the dose of indomethacin. Of the 33 measurements made before the indomethacin was given, only two were more than 6 $\mathrm{kPa}(1 \mathrm{kPa}=7.5 \mathrm{~mm} \mathrm{Hg})$. At these times, when

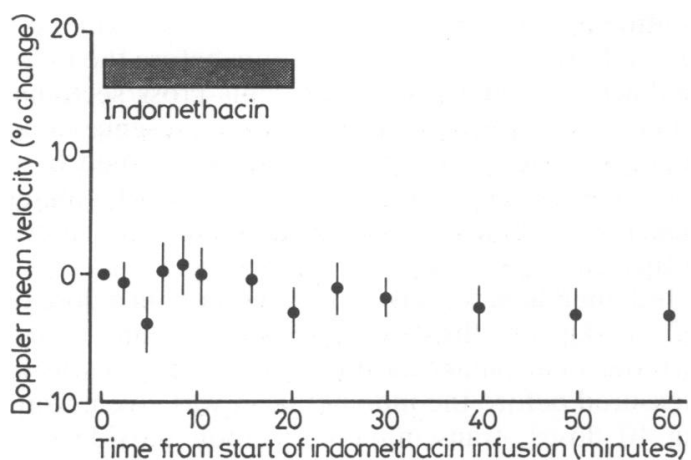

Fig 3 Percentage change of Doppler mean flow velocity in the anterior cerebral artery after indomethacin infusion over 20 minutes. Figures are mean (SE).

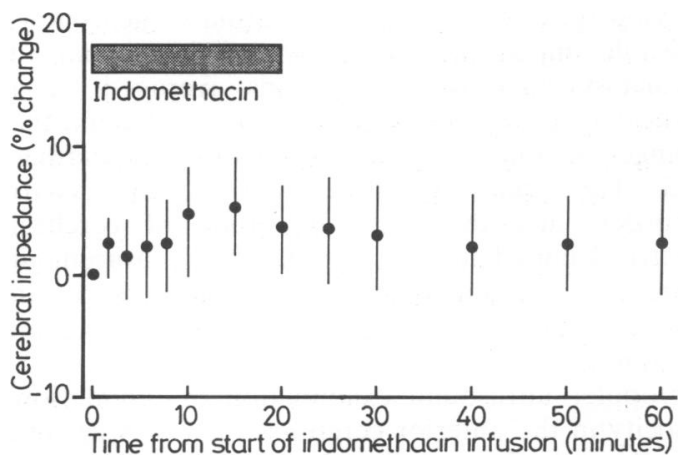

Fig 4 Percentage change in cerebral electrical impedance peak amplitude after indomethacin infusion over 20 minutes. Figures are mean (SE).

carbon dioxide tensions were $7 \cdot 1$ and $7 \cdot 8 \mathrm{kPa}$, the changes in Doppler mean flow velocity and cerebral electrical impedance were similar to the response in the same patient when carbon dioxide tension was $<6 \mathrm{kPa}$. Multiple linear regression analysis of gestational age and postnatal age, with the mean maximum response of Doppler mean flow velocity and cerebral electrical impedance used sequentially as the dependent variable, showed no significant effect of either of these variables on response after indomethacin infused over five minutes.

The repeatability coefficient of Doppler mean flow velocity was $0.59 \mathrm{~cm} / \mathrm{s}$ (mean $7.19 \mathrm{~cm} / \mathrm{s}$ ) and of cerebral electrical impedance was $2.4 \mathrm{mOhm}$ (mean $22.2 \mathrm{mOhm}$ ). In $95 \%$ of cases therefore, assuming that the variable had not changed, repeated measurements could be expected to be within $16 \%$ of one another for Doppler mean flow velocity and within $22 \%$ for cerebral electrical impedance. 


\section{Discussion}

The early reduction in Doppler mean flow velocity after the five minute infusion of indomethacin is similar to previously published results. ${ }^{1011}$ Cerebral blood flow decreases within two minutes in newborn animals. ${ }^{17-19}$ This change is dose dependent, and in the newborn dog is about $20 \%$ with the dose used in this study, ${ }^{14}{ }^{24}$ which may be just enough to affect the cerebral circulation when infused rapidly but may not have an effect after slower infusion where instantaneous brain blood concentrations are lower. No previous studies have addressed the effect of different infusion rates on cerebrovascular responses. Another possible explanation as to why there was a difference in response after infusion at the two rates is that there was a difference in the two study groups. There were, however, no differences between the groups in gestational age, postnatal age, birth weight, carbon dioxide tension at the start of the infusion, and clinical state.

Whether there are any potentially deleterious effects of a reduction in cerebral blood flow associated with treatment with indomethacin is unknown. In experiments in animals, decreases in cerebral blood flow associated with indomethacin have not been associated with a reduction in cerebral metabolic rates of oxygen or glucose. 132526

The repeatability coefficients of both Doppler mean flow velocity and cerebral electrical impedance suggest that the reduction after the five minute infusion of indomethacin was not likely to have been accounted for by measurement variability. Results of both techniques suggest reductions in cerebral blood flow ${ }^{27}$ of about the same magnitude as seen in newborn animals ${ }^{15}$ and humans. ${ }^{12}$

Hypercapnia, postnatal age, and gestational age may affect the magnitude of the cerebrovascular response after infusion of indomethacin. Cerebral blood flow is reduced more when there is hypercapnia ${ }^{2628} 29$ but no similar effect of carbon dioxide tension was seen in this study on Doppler mean flow velocity or cerebral electrical impedance. In newborn dogs postnatal age is an important determinant of the magnitude of cerebrovascular response, but we saw no such effect. No studies have directly addressed the effect of gestational age on cerebrovascular responses but it seems likely that responses should be greater at lower gestational age down to an unknown lower limit. ${ }^{15}$ We did not observe an effect of gestational age.

Indomethacin has effects on blood pressure control mediated by the autonomic nervous and renin angiotensin systems. ${ }^{30}{ }^{31}$ Evans et al $^{11}$ found a mean increase of $15 \%$ in blood pressure in the neonate after indomethacin had been given. In this study there was no consistent change in blood pressure after infusion at either rate.

The efficacy of indomethacin in closing the patent ductus arteriosus was not examined in this study, but it seems to be associated with steady state serum concentration..$^{3-6}$ Because the half life of indomethacin in the neonate is at least eight hours and usually about 20 hours $^{36}$ there should be no difference in serum concentrations after infusion at the different rates used in this study, and hence efficacy would be expected to be the same.

We recommend that in clinical practice and in studies to determine optimal dosage schedules indomethacin be infused over 20 minutes or longer. Until further data are available there must be concern about the possible deleterious effects of the apparent reduction in cerebral blood flow observed with shorter infusion periods.

PC received financial support from the Medical Foundation, University of Sydney, Australia.

\section{References}

1 Silove ED. Pharmacological manipulation of the ductus arteriosus. Arch Dis Child 1986;61:827-9.

2 Goldberg SJ. Response of the patent ductus arteriosus to indomethacin treatment. Am J Dis Child 1987;141:250.

3 Yaffe SJ, Friedman WF, Rogers D, Lang P, Ragni M, Saccar C. The disposition of indomethacin in preterm babies. $J$ Pediatr 1980;97:1001-6.

${ }^{4}$ Brash AR, Hickey DE, Graham TP, Stahlman MT, Oates JA, Cotton RB. Pharmacokinetics of indomethacin in the neonate. $N$ Engl J Med 1981;305:67-72.

5 Yeh TF, Luken J, Raval D, Thalji A, Carr I, Pildes RS. Indomethacin treatment in small versus large premature infants with ductus arteriosus. Br Heart $J$ 1983;50:27-30.

${ }^{6}$ Seyberth HW, Knapp G, Wolf D, Ulmer HE. Introduction of plasma indomethacin level monitoring and evaluation of an effective threshold level in very low birth weight infants with symptomatic patent ductus arteriosus. Eur $J$ Pediatr 1983;141:71-6.

7 Peckham GJ, Miettinen OS, Ellison RC, et al. Clinical course to one year of age in premature infants with patent ductus arteriosus: results of a multicentre trial of indomethacin. J Pediatr 1984;105:285-91.

${ }^{8}$ Mahony L, Caldwell RL, Girod DA, et al. Indomethacin therapy on the first day of life in infants with very low birth weight. J Pediatr 1985;106:801-5.

9 Rennie JM, Doyle J, Cooke RW. Early administration of indomethacin to preterm infants. Arch Dis Child 1986;61:233-8.

10 Cowan F. Indomethacin, patent ductus arteriosus, and cerebral blood flow. J Pediatr 1986;109:341-4.

11 Evans DH, Levene MI, Archer LNJ. The effect of indomethacin on cerebral blood flow velocity in premature infants. Dev Med Child Neurol 1987;29:776-82.

12 Pryds O, Greisen G, Johansen KH. Indomethacin and cerebral blood flow in premature infants treated for patent ductus arteriosus. Eur J Pediatr 1988;147:315-6.

13 Hohimer AR, Richardson BS, Bissonette JM, Machida CM. The effect of indomethacin on breathing movements and cerebral blood flow and metabolism in the fetal sheep. $J$ Dev Physiol 1985;7:217-28.

14 Leffler CW, Busija DW. Arachidonate metabolism on the cerebral surface of newborn pigs. Prostaglandins 1985;30:811-8. 
12 Colditz, Murphy, Rolfe, and Wilkinson

15 Leffler CW, Busija DW. Arachidonic acid metabolites and perinatal cerebral hemodynamics. Semin Perinatol 1987;11: $31-42$.

16 Ment LR, Stewart WB, Duncan CC, Scott DT, Lambrecht R. Beagle puppy model of intraventricular hemorrhage: effect of indomethacin on cerebral blood flow. J Neurosurg 1983;58: 857-62.

17 Pickard JD, Tamura A, Stewart M, et al. Prostacyclin, indomethacin and the cerebral circulation. Brain Res 1980;197:425-31.

18 Dahlgren N, Siesjo BK. Effects of indomethacin on cerebral blood flow and oxygen consumption in barbiturateanaesthetized normocapnic and hypercapnic rats. J Cereb Blood Flow Metab 1981;1:109-15.

19 Crockard HA, Iannotti F, Ladds G. Cerebrovascular effects of prostaglandin inhibitors in the gerbil. J Cereb Blood Flow Metab 1982;2:67-72.

${ }^{20}$ Hagen AA, White RP, Robertson JT. Synthesis of prostaglandins and thromboxane $\mathrm{B}_{2}$ by cerebral arteries. Stroke 1979;10:306-9.

21 Colditz P, Pryds O, Greisen G, Murphy D, Rolfe P, Wilkinson AR. Cerebral electrical impedance: do indices derived from it provide information on cerebral blood flow in the neonate? Scand J Clin Lab Invest (in press).

22 Colditz P, Greisen G, Pryds O. Comparison of electrical impedance and ${ }^{133}$ xenon clearance for the assessment of cerebral blood flow in the newborn infant. Pediatr Res (in press).

23 Bland JM, Altman DG. Statistical methods for assessing agreement between two methods of clinical measurement. Lancet 1986;i:307-10.

${ }^{24}$ Leffler CW, Busija DW, Beasley DG. Effect of therapeutic dose of indomethacin on the cerebral circulation of newborn pigs. Pediatr Res 1987;21:188-92.

25 McCulloch J, Kelly PAT, Grome JJ, Pickard JD. Local cerebral circulatory and metabolic effects of indomethacin. Am J Physiol 1982;243:H416-23.

${ }^{26}$ Eriksson S, Hagenfeldt L, Law D, Patrono C, Pinca E, Węnnmalm A. Effect of prostaglandin synthesis inhibitors on basal and carbon dioxide stimulated cerebral blood flow in man. Acta Physiol Scand 1983;117:203-11.

27 Greisen G, Johansen K, Ellison PH, Fredricksen PS, Mali J, Friis-Hansen B. Cerebral blood flow in the newborn infant: Comparison of Doppler ultrasound and 133-xenon clearance. J Pediatr 1984;104:411-7.

${ }^{28}$ Sakabe T, Siesjo BK. The effect of indomethacin on the blood flow-metabolism couple in the brain under normal, hypercapnic and hypoxic conditions. Acta Physiol Scand 1979;107:283-4.

29 Busija DW, Heistad DD. Effects of indomethacin on cerebral blood flow during hypercapnia in cats. Am J Physiol 1983;244:H519-H524.

30 Anderson RJ, Berl T, McDonald KM, Schrier RW. Prostaglandins: effects on blood pressure, renal blood flow, sodium and water excretion. Kidney Int 1976;10:205-15.

31 Dusting GJ, Moncada S, Vane JR. Prostaglandins, their intermediates and precursors: cardiovascular actions, and regulatory roles in normal and abnormal circulatory systems. Prog Cardiovasc Dis 1979;21:405-30.

Correspondence and requests for reprints to Dr AR Wilkinson, Neonatal Unit, John Radcliffe Hospital, Oxford OX3 9DU.

Accepted 28 July 1988 